\title{
Analysis of Understanding The Use of Javanese Language "Krama Inggil" of Preservice Teachers in Primary Teacher Education Programs
}

\author{
Ngatman \\ Universitas Sebelas Maret \\ ngatman@fkip.uns.id
}

Article History

accepted 24/09/2019

\begin{abstract}
This study aims to analyze the understanding the use of Javanese language "krama inggil" of preservice teachers in primary teacher education programs. This research is a descriptive study of 84 research subjects. The instruments used were description test sheets, questionnaire sheets, and interview sheets. The data analysis technique uses descriptive qualitative. The results of the analysis show that: 1) The average value of understanding the use of Javanese language "krama inggil" was 78; 2) students who are able to communicate using good manners and apply in daily life as much as $38.61 \%$; 3) Some of the difficulties factors of students using Javanese language "krama inggil" include not being accustomed from childhood, parents do not teach Javanese language "krama inggil", preferring to use Indonesian, lacking the motivation to use Javanese language "krama inggil" because it is difficult to pronounce.
\end{abstract}

Keywords: understanding of the Javanese language "krama inggil"

\section{Abstrak}

Penelitian ini bertujuan untuk menganalisis pemahaman penggunaan bahasa jawa "krama inggil" mahasiswa PGSD Kebumen. Penelitian ini merupakan penelitian deskriptif dengan subyek penelitian berjumlah 84 mahasiswa PGSD Kebumen. Instrumen yang digunakan berupa lembar tes uraian, lembar angket, dan lembar intreview. Teknik analisis data menggunakan deskriptif kualitatif. Hasil analisis menunjukkan bahwa: 1) Rata-rata nilai pemahaman penggunaan bahasa Jawa krama inggil mahasiswa adalah sebesar sebesar 78; 2) mahasiswa yang mampu berkomunikasi menggunakan bahasa krama inggil dengan baik dan mengaplikasikan dalam kehidupan sehari-hari hanya sebesar 38,61\%; 3) Beberapa faktor kesulitan dari mahasiswa menggunakan bahasa krama inggil antara lain tidak dibiasakan dari kecil, orang tua tidak mengajarkan bahasa krama inggil, lebih senang menggunakan bahasa Indonesia, kurang motivasi untuk menggunakan bahasa krama inggil karena sulit diucapkan.

Kata kunci: pemahaman bahasa Jawa krama inggil

Social, Humanities, and Education Studies (SHEs): Conference Series https://jurnal.uns.ac.id/shes 


\section{PENDAHULUAN}

Indonesia memiliki banyak keanekaragaman budaya yang menjadi alat pemersatu. Bahasa adalah salah satu aspek budaya yang sangat penting karena menjadi alat komunikasi antara manusia yang satu dengan manusia yang lain untuk saling berinteraksi. Bahasa di masing-masing daerah memiliki ciri khas dan kaidah masing-masing. Bahasa Jawa merupakan salah satu bahasa daerah yang kaya akan makna dan ajaran sopan santun (Mayangsari, dkk: 2015). Bentuk unggah-ungguh bahasa Jawa yang selama ini dikenal secara luas oleh masyarakat Jawa adalah bentuk ngoko dan bentuk krama. Bentuk krama sering disebut juga dengan kata basa maksudnya jika ada seseorang yang tidak menggunakan bentuk krama dengan benar, maka orang itu akan disebut sebagai orang yang tidak bisa menggunakan bahasa Jawa secara halus (Ratnasari \& Jadmiko, 2018). Sasangka (2010) menjelaskan bahwa ungguh ungguh bahasa Jawa merupakan suatu tingkatan dalam tuturan kata yang terdapat dalam Bahasa Jawa. Ungguh ungguh bahasa Jawa pada prinsipnya terdiri atas empat macam, yaitu basa ngoko (ngoko lugu dan alus), krama (krama lugu dan alus).

Krama alus atau sering disebut juga dengan krama inggil merupakan bagian dari penuturan bahasa Jawa yang memiliki tingkatan tertinggi. Hal ini dikarenakan, bahasa Jawa krama inggil dipergunakan untuk memberikan penghormatan kepada lawan bicara yang lebih tua dan layak untuk diberi penghormatan (Ratnasari \& Jadmiko, 2018). Di era globalisasi, penggunaan bahasa Jawa krama inggil untuk menjadi sarana komunikasi semakin luntur. Hal ini juga terlihat pada mahasiswa PGSD Kebumen sekarang yang cenderung berkurang menggunakan bahasa Jawa krama inggil dalam berkomunikasi ke dosen dan karyawan. Mahasiswa lebih banyak menggunakan bahasa Indonesia atau campuran antara bahasa Indonesia dan bahasa Jawa krama inggil. Ketika ada yang menggunakan bahasa Jawa krama inggil, masih banyak penggunaan kata yang tidak tepat.

Penggunaan bahasa Jawa krama inggil harus selalu dijaga dan dilestarikan agar tidak hilang atau punah. Suryadi (2014) menyebutkan bahwa di zaman sekarang minat penggunaan bahasa Jawa krama Inggil semakin berkurang sehingga diperlukan upaya dalam menjaga bahasa daerah. Melalui penggunaan bahasa Jawa krama inggil untuk alat berkomunikasi dalam kehidupan sehari-hari adalah salah satu cara yang efektif dalam melestarikan bahasa daerah. Yati (2015) menyebutkan bahwa pentingnya dalam menjaga kelestarian bahasa daerah dikarenakan bahasa memiliki jalinan yang sangat erat dengan budaya sehingga keduanya tidak bisa dipisahkan. Tanpa bahasa, budaya pun akan mati. Purwo (2003) menjelaskan bahwa bahasa adalah penyangga budaya, sebagian besar budaya terkandung di dalam bahasa dan diekspresikan melalui bahasa. Penjelasan ini juga diperkuat dalam peraturan pemerintah RI No 57 tahun 2014 bahwa bahasa daerah berfungsi sebagai pembentuk kepribadian suku bangsa, peneguh jati diri kedaerahan, dan sarana pengungkapan serta pengembangan sastra dan budaya daerah dalam bingkai keindonesiaan. Dalam rangka melestarikan bahasa daerah tersebut, pemerintah secara tegas membuat peraturan tentang penggunaan bahasa daerah di wilayah masing-masing daerah yaitu dengan mencanangkan program unggulan yakni (1) pemetaan, (2) kajian vitalitas, (3) konservasi, (4) revitalisasi, dan (5) registrasi bahasa. 


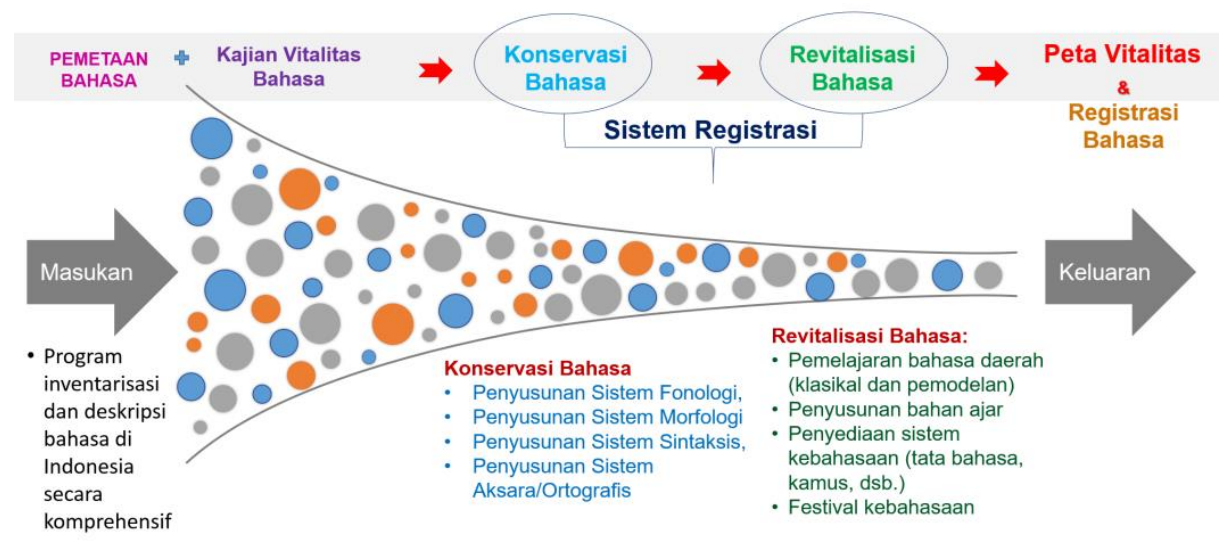

Gambar 1. Garis Besar Program Pelindungan Bahasa

(Sumber: http://badanbahasa.kemdikbud.go.id/)

Berdasarkan penjelasan di atas, tujuan dalam penelitian ini adalah menganalisis pemahaman penggunaan bahasa Jawa krama inggil mahasiswa PGSD Kebumen dan faktor-faktor yang mempengaruhi penggunaan bahasa Jawa krama inggil.

\section{METODE}

Penelitian ini merupakan penelitian deskriptif dengan subyek penelitian mahasiswa semester 6 PGSD Kebumen yang berjumlah 84 mahasiswa. Instrumen yang digunakan meliputi lembar tes uraian, lembar angket, dan lembar intreview. Teknik analisis data menggunakan deskriptif kualitatif. Lembar tes terdiri dari tes uraian berupa cerita singkat yang diambil dari majalah "Panjebar Semangat" edisi 16/2/2019 dengan judul artikel "Teror Ngobong Kendharaan". Lembar angket yang digunakan adalah bentuk skala likert dengan empat kriteria, yaitu Sangat Setuju (SS), Setuju (S), Tidak Setuju (TS), dan Sangat Tidak Setuju (STS) dengan jumlah sebanyak 15 item pernyataan. Untuk mengetahui kriteria pemahaman penggunaan bahasa jawa "krama inggil" menggunakan kriteria seperti pada tabel 1.

Tabel 1. Kriteria Pemahaman Penggunaan Bahasa

\begin{tabular}{ccc}
\hline No & Rentang Nilai & Kriteria \\
\hline 1 & $80-100$ & Sangat Baik \\
2 & $66-79$ & Baik \\
3 & $56-65$ & Cukup \\
4 & $40-55$ & Kurang \\
5 & $\leq 39$ & Gagal \\
\hline \multicolumn{2}{l}{ (Sumber: diadaptasi dari Arikunto, 2009) }
\end{tabular}

Sedangkan untuk mengetahui jumlah persentase penggunaan bahasa dapat dilihat pada persamaan 1.

$$
\text { Penggunaan Bahasa }(\%)=\frac{\text { Jumlah skoryang didapatkan }}{\text { skor maksimal }} \times 100 \% \quad \text { (Pers. 1) }
$$




\section{HASIL DAN PEMBAHASAN}

Penelitian mengenai ungguh ungguh bahasa ini memfokuskan pada ketidaktepatan mahasiswa dalam penggunaan bahasa Jawa krama inggil yaitu dengan menyelesaikan soal uraian. Berdasarkan analisis jawaban mahasiswa, masih banyak ditemukan adanya ketidaksesuaian dari aspek kebahasaan yaitu pada penggunaan diksi. Hasil rata-rata nilai pemahaman yang didapatkan mahasiswa adalah sebesar 78 yaitu termasuk kategori baik. Sedangkan jika meninjau hasil dari angket, hanya sebesar 38,61\% mahasiswa yang mampu menggunakan bahasa Jawa krama inggil dengan baik dan biasa mengaplikasikan dalam kehidupan sehari-hari. Berdasarkan hasil wawancara, banyaknya kesalahan dalam penggunaan diksi di soal uraian adalah mahasiswa masih merasa bingung membedakan antara krama inggil dan krama lugu, banyak ditemukan kesalahan penggunaan awalan ngoko pada ujaran yang menggunakan krama alus. Bentuk krama inggil seharusnya digunakan untuk lawan bicara, orang yang berbicara seharusnya merendah, karena kedudukannya lebih muda daripada lawan bicara. Hal ini sejalan dengan penelitian Mayangsari, dkk (2015) bahwa kesalahan dalam penggunaan bahasa jawa krama alus yang paling banyak adalah penggunaan diksi terutama pada bagian bentuk krama inggil yang seharusnya digunakan untuk lawan bicara (yang lebih tua/dihormati).

Beberapa faktor yang mempengaruhi kesalahan dalam penggunaan bahasa Jawa krama inggil adalah keterbatasan diksi yang dimiliki oleh mahasiswa. Hal ini disebabkan oleh beberapa hal, salah satunya adalah kurangnya pembiasaan penggunaan bahasa Jawa krama inggil dalam kehidupan sehari-hari. Terlebih adanya peningkatan penggunaan bahasa Indonesia yang digunakan baik ketika komunikasi ke orang yang lebih tua ataupun juga ke teman sejawat. Secara pengucapan, penggunaan bahasa Indonesia dirasa lebih mudah dipahami dan digunakan dalam percakapan karena tidak terlalu memikirkan jenjang usia dan derajat. Faktor selanjutnya adalah kurangnya pemahaman akan tingkatan tutur yang terdiri dari empat tingkatan, yaitu ngoko lugu, ngoko alus, krama lugu, dan krama alus (inggil). Mahasiswa masih mengalami kesulitan dalam membedakan tingkatan tutur tersebut sehingga menyebakan mahasiswa menjadi khawatir dan takut dalam menggunakan unggah ungguh bahasa Jawa dalam percakapan kehidupan sehari-hari.

Faktor lingkungan menjadi faktor yang sangat berpengaruh terhadap penggunaan bahasa Jawa krama inggil. Ketika di lingkungan banyak yang menggunakan bahasa Indonesia daripada bahasa Jawa krama, maka secara otomatis untuk menjaga komunikasi agar tetap baik adalah dengan menggunakan bahasa Indonesia. Terlebih di lingkungan keluarga juga kurang adanya pembiasaan penggunaan bahasa Jawa krama inggil, akan semakin menghilangnya bahasa Jawa krama inggil sebagai bahasa percakapan. Hal ini sejalan dengan penelitian Ratnasari \& Jadmiko (2018) yang menyatakan bahwa kesalahan-kesalahan dalam menggunakan bahasa Jawa krama inggil adalah salah satunya karena kurangnya orang tua yang menggunakan bahasa krama apabila berbicara dengan orang lain yang memiliki usia lebih tua darinya bahkan cenderung sering menggunakan bahasa Indonesia. Istiyana (2015) juga menyebutkan bahwa lingkungan keluarga sangat mempengaruhi bisa tidaknya seseorang menggunakan bahasa Jawa krama alus. Saddhono \& Rohmadi (2014) menekankan bahwa bahasa ibu adalah bahasa yang sangat berpengaruh pada perkembangan bahasa anak.

\section{SIMPULAN}

Hasil analisis menunjukkan bahwa: 1) pemahaman penggunaan bahasa krama inggil mahasiswa PGSD Kebumen menunjukkan kategori baik dengan rata-rata nilai sebesar 78; 2) mahasiswa yang mampu berkomunikasi menggunakan bahasa krama inggil dengan baik dan mengaplikasikan dalam kehidupan sehari-hari hanya sebesar $38,61 \%$; 3) Beberapa faktor kesulitan dari mahasiswa menggunakan bahasa krama 
inggil antara lain tidak dibiasakan dari kecil, orang tua tidak mengajarkan bahasa Jawa krama inggil, lebih senang menggunakan bahasa Indonesia, kurang motivasi untuk menggunakan bahasa Jawa krama inggil karena sulit diucapkan dan harus memperhatikan kaidah/unggah ungguh pengucapan. Ditinjau dari pengetahuan teori, mahasiswa memiliki pemahaman yang baik namun kurang dalam mengaplikasikan bahasa Jawa krama Inggil menjadi alat komunikasi. Sehingga diperlukan adanya pembiasaan yang dilakukan secara kontinyu.

\section{DAFTAR PUSTAKA}

Arikunto, S. (2009). Manajemen Penelitian. Jakarta: Rineka Cipta.

Istiyana, R. N. (2015). Meningkatkan Penggunaan Bahasa Jawa Krama Alus dengan Media Sosial Bagi Siswa kelas X RA di SMK Negeri 2 Karanganyar. Laporan Hasil Penelitian IImiah.

Mayangsari, T., Waluyo, B., \& Rahmat. (2015). Analisis Kesalahan Berbahasa pada Penggunaan Unggah-Ungguh Basa Dalam Wacana Dialog Karangan Siswa Kelas VII SMP Negeri 16 Surakarta. Skripsi: UNS.

Purwo, B. K. (2000). Bangkitnya Kebinekaan: Dunia Linguistik dan Pendidikan. Jakarta: Mega Media Abadi.

Ratnasari, K.N., \& Jadmiko, R.S. (2018). Analisis Penggunaan Bahasa Krama Inggil dari Orang Tua Terhadap Nilai Kesopanan Anak di Desa Ariyojed Rejotangan Tulungagung. Jurnal Pendidikan Karakter, Tahun VIII (2), 152-160.

Saddhono, K., \& Rohmadi, M. (2014). A Sociolinguistics Study on the Use of the Javanese Languange in the Learning Process in Primary Schools in Surakarta. International Education Studies, Vol 7 (6), 25-30.

Sasangka, S.S.T.W. (2010). Unggah-Ungguh Bahasa Jawa. (Y. Maryani, Ed.) (4th ed.). Jakarta: Yayasan Paramalingua.

Suryadi, M. (2014). The Use of Krama Inggil (Javanese Language) in Family Domaain at Semarang and Pekalongan Cities. International journal of Linguistics, Vol 6 (3), 243-256.

Yati, D. (2015). Menyelamatkan Bahasa Daerah Melalui Pembelajaran Bahasa yang Komunikatif. Prosiding Seminar Nasional Bulan Bahasa UNIB, 157-170. 